\title{
RESEARCH
}

\section{Joint contracture following prolonged stay in the intensive care unit}

\author{
Heidi Clavet BScPT, Paul C. Hébert MD MHSc, Dean Fergusson PhD, Steve Doucette MSc, \\ Guy Trudel MD
}

$\infty \quad$ See related article page 725

\section{ABSTRACT}

Background: Prolonged immobility during a critical illness may predispose patients to the development of joint contracture. We sought to document the incidence of, the risk factors for and the reversibility of joint contractures among patients who stayed in a tertiary intensive care unit (ICU) for 2 weeks or longer.

Methods: We conducted a chart review to collect data on the presence of and risk factors for joint contractures in the shoulders, elbows, hips, knees and ankles among patients admitted to the ICU between January 2003 and March 2005.

Results: At the time of transfer out of the ICU, at least 1 joint contracture was recorded in 61 (39\%) of 155 patients; 52 ( $34 \%)$ of the patients had joint contractures of an extent documented to impair function. Time spent in the ICU was a significant risk factor for contracture: a stay of 8 weeks or longer was associated with a significantly greater risk of any joint contracture than a stay of 2 to 3 weeks (adjusted odds ratio [OR] 7.09, 95\% confidence interval $(\mathrm{CI})$ 1.29-38.9; $p=$ 0.02 ). Among the variables tested, only the use of steroids conferred a protective effect against joint contractures (adjusted OR $0.35,95 \% \mathrm{Cl} 0.14-0.83 ; p=0.02$ ). At the time of discharge to home, which occurred a median of 6.6 weeks after transfer out of intensive care, 50 (34\%) of the 147 patients not lost to follow-up still had 1 or more joint contractures, and 34 (23\%) of the patients had at least 1 functionally significant joint contracture.

Interpretation: Following a prolonged stay in the ICU, a functionally significant contracture of a major joint occurred in more than one-third of patients, and most of these contractures persisted until the time of discharge to home.

Une version française de ce résumé est disponible à l'adresse www.cmaj.ca/cgi/content/full/I78/6/69I/DCI

CMAJ 2008;178(6):69I-7

oint contracture is a limitation in the passive range of motion of a joint secondary to shortening of the periarticular connective tissues and muscles. ${ }^{1-7}$ Immobility plays a major role in the development of joint contractures. ${ }^{1,2,6,8-13}$ Indeed, patients with conditions limiting mo- bility are at high risk for joint contracture..$^{1,9,14,15}$ Prolonged immobility from critical illness can also be expected to predispose patients to experience joint contractures. Herridge and colleagues ${ }^{13}$ evaluated the long-term consequences of acute lung injury and noticed the disabling effects of joint contractures in a small number of patients in the first year after discharge from an acute care hospital. In a systematic review, we were unable to identify any other studies characterizing joint mobility after critical illness. ${ }^{16}$

Given the potentially devastating consequences of joint contracture after a prolonged stay in the intensive care unit (ICU), we sought to document the incidence of this problem among patients who remained in an ICU for 2 weeks or more. We were especially interested in mild, as well as functionally significant, limitation in the range of motion of major joints and in the number of joints affected. We also examined risk factors and the persistence or reversibility of joint contractures until discharge from hospital.

\section{Methods}

\section{Study design and participants}

We conducted a retrospective evaluation of hospital records for consecutive patients admitted to the ICU of a tertiary care hospital between January 2003 and March 2005. We included patients who stayed in the ICU for I4 days or more and who survived until transfer out of the unit. We retrieved records from the hospital's ICU database and extracted all charts that met our inclusion criteria. No patients were eliminated during the course of the study. The protocol for this project was approved by the Ottawa Hospital Research Ethics Board, The Rehabilitation Centre Ethics Board and the SCO Health Services Research Ethics Board.

\section{Data collection and outcomes}

We examined all chart entries for medical care, physiotherapy and occupational therapy. We extracted bilateral numeric range-of-motion data for 5 large joints: the shoulder, elbow,

From the Bone and Joint Laboratory (Clavet, Trudel) and the Department of Medicine (Hébert, Fergusson, Trudel), University of Ottawa, Ottawa, Ont.; the Clinical Epidemiology Program of the Ottawa Hospital (Clavet, Fergusson, Doucette), Ottawa Health Research Institute, Ottawa, Ont.; and the Department of Critical Care, The Ottawa Hospital (Hébert), Ottawa, Ont. 
hip, knee and ankle. We tabulated the range of motion for the left and right sides, as well as 2 directions of movement for each joint, except the ankle, for which we extracted only lack of dorsiflexion. Diagnosis of a joint contracture required documentation of a measurement of range of motion; a progress note stating "patient had a contracture" or "bilateral ankle contracture" was not counted.

On the basis of the existing literature, we defined contracture in 2 ways. First, we defined "any contracture" as a recorded range of motion that was short of the full range. ${ }^{17-21}$ This definition reflects the fact that the activities of people with physical occupations and recreational or performance athletes will be limited by even small limitations in the range of motion of key joints. ${ }^{22-25}$ It also allowed us to quantify a potential dose-effect relation between exposure to the ICU and severity of limitation in the range of motion. In addition, we defined "functionally significant contracture" as more severe limitation in the range of motion, to an extent that has been established in the literature as causing functional limitation $^{8,17,19,21,26}$ (Table I). We recorded any contractures, functionally significant contractures, patients with at least I contracture, number of joint contractures per patient and the total number of joints with contractures.

For each patient, we sought range-of-motion data at 2 time points: at transfer out of the ICU and before discharge to home (patient's home, a nursing home or a regional hospital). Range of motion before discharge was recorded from the last medical unit before discharge to home.

In addition, we collected data on patient demographic characteristics, comorbidities, admission diagnosis, Acute Physiology and Chronic Health Evaluation (APACHE II) severity score ${ }^{27}$ on admission, length of stay in the ICU, duration of

Table 1: Definitions from the literature of "contracture" and "functionally significant contracture" at the shoulder, elbow, hip, knee and ankle

Type of contracture;

range of motion of joint, in degrees

\begin{tabular}{|c|c|c|}
\hline Joint & Contracture & $\begin{array}{c}\text { Functionally significant } \\
\text { contracture }\end{array}$ \\
\hline \multicolumn{3}{|l|}{ Shoulder ${ }^{17}$} \\
\hline Flexion & $96-179$ & $0-95$ \\
\hline Abduction & $96-179$ & $0-95$ \\
\hline \multicolumn{3}{|l|}{ Elbow $^{18,26}$} \\
\hline Flexion & $131-164$ & $90-130$ \\
\hline Lack of extension & $1-29$ & $30-90$ \\
\hline \multicolumn{3}{|l|}{ Hip $^{19}$} \\
\hline Flexion & $91-119$ & $0-90$ \\
\hline Extension & $5-14$ & $<5$ \\
\hline \multicolumn{3}{|l|}{ Knee $^{8,19,20}$} \\
\hline Flexion & $91-159$ & $0-90$ \\
\hline Lack of extension & $0-9$ & $>9$ \\
\hline \multicolumn{3}{|l|}{ Ankle 21} \\
\hline Dorsiflexion & 0-19 & $<0$ \\
\hline
\end{tabular}

invasive mechanical ventilation, use of co-interventions (specifically, neuromuscular blockade and steroids) and total length of the hospital stay.

\section{Statistical analysis}

Patient demographic characteristics were summarized as frequencies and percentages for categorical variables. Continuous data are displayed as mean (standard deviation [SD]).

Two separate multiple logistic regression analyses were undertaken to evaluate the odds of experiencing any contracture and a functionally significant contracture, both determined at the time of transfer out of the ICU and before discharge to home. All independent variables that were considered clinically relevant by the study investigators were included in both analyses, specifically age $(<45,45-65,>65$ years), sex, presence of diabetes mellitus, admission diagnoses (acute or chronic respiratory disease, cancer, neurologic or vascular disease, or sepsis), APACHE II severity score ( $<15,15-25,>25)$, length of stay in the ICU $(2-2.99,3-4.99$, $5-7.99, \geq 8$ weeks), duration of invasive mechanical ventilation ( $<$ IO, IO-I9, $\geq 20$ days), use of neuromuscular blockade or steroids as co-interventions (given v. not given) and length of hospital stay $(<4,4-7.99, \geq 8$ weeks).

\section{Results}

In total, 155 patients met the inclusion criteria (Figure I). Their mean age was 59.6 [SD I5.5] years (Table 2). The mean length of stay in the ICU was 3.1 ( $95 \%$ confidence interval [CI 2.4-5.0) weeks. While in the ICU, at least I contracture was reported for $6 \mathrm{I}(39 \%)$ of the patients, and $52(34 \%)$ of the patients had a contracture that met the criteria for functional significance.

At the time of transfer out of the ICU, a total of 212 major joints representing 6r patients were affected by any joint contracture, of which 144 joints (68\%) were affected by a functionally significant contracture (Table 3 ). The elbow was the joint most frequently affected by any contracture ( $76[35.8 \%$ of the total number of joints affected]), followed by the ankle (5I [24.I\%]), the knee (3I [I4.6\%]), the hip (30 [14.2\%]) and the shoulder (24 [II.3\%]) (Table 3).

Each affected patient had an average of 3.5 joint contractures at the time of transfer out of the ICU, of which 2.4 contractures were functionally significant.

Time in the ICU was a significant risk factor for the development of any joint contracture. Among patients who remained in the ICU for 8 weeks or more, the adjusted odds ratio of experiencing any joint contracture was 7.09 (95\% CI I.29-38.9; $p=0.02$ ) relative to those who stayed for 2 to 3 weeks (Figure 2). Similarly, the adjusted OR of experiencing a functionally significant contracture after 8 weeks or more in the ICU was 5.79 (95\% CI I.08-3I.0; $p=0.04$ ) relative to a stay of 2 to 3 weeks (Figure 3). Receiving steroids while in the ICU was associated with lower odds of developing any joint contracture (OR $0.35,95 \% \mathrm{CI} 0.14-0.83 ; p=0.02$ ) (Figure 2). The other variables tested (age, sex, admission diagnosis, diabetes mellitus as a comorbidity, duration of invasive mechanical ventilation and use of neuromuscular 


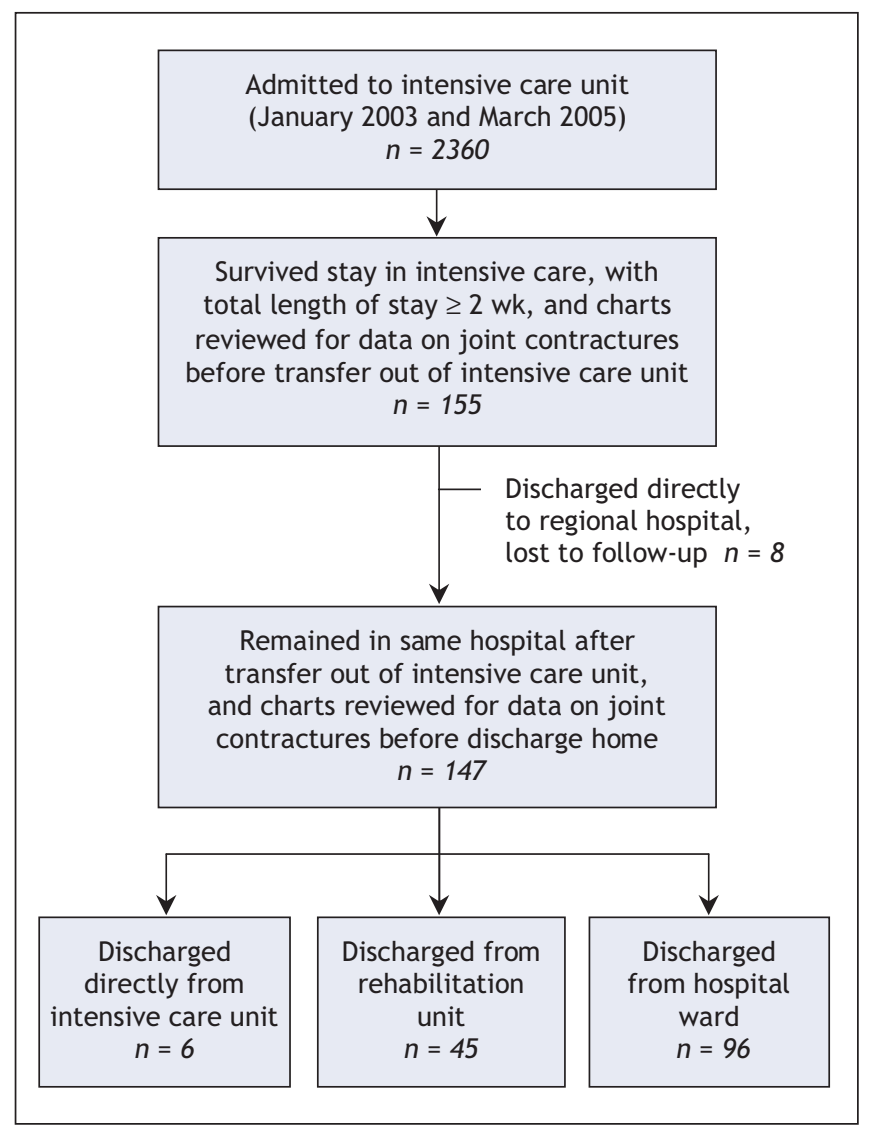

Figure 1: Flow diagram for patient recruitment. Discharge home means discharge to the patient's home, a nursing home or a regional hospital.

blockers) did not affect the risk of experiencing any joint contracture or a functionally significant joint contracture (Figure 2 and Figure 3).

After transfer out of the ICU, 8 patients were sent to a regional hospital and were lost to follow-up (Figure I). The other patients were discharged to home directly from the ICU $(n=6)$, from the hospital ward $(n=96)$ or from a rehabilitation unit $(n=45)$; the median time until discharge to home after transfer out of the ICU was 6.6 weeks.

Upon discharge home, 50 (34\%) of the 147 patients still had at least I joint contracture, and $34(23 \%)$ of the I47 patients had at least I functionally significant contracture (Table 3). Of the 182 joint contractures that were still present at the time of discharge to home, 90 were functionally significant (Table 3). Among the 50 affected patients not lost to follow-up who had at least I contracture at the time of discharge to home, the mean number of contractures at that time was 3.6 per patient, and the mean number of functionally significant contractures was I.8.

\section{Interpretation}

More than one-third of patients who stayed for 2 weeks or longer in the ICU had a functionally significant joint contracture. On average, these patients each had more than 2 func- tionally significant joint contractures. The duration of the ICU stay was associated with the presence of any joint contractures at the time of transfer out of intensive care. At 2 weeks, these patients were already experiencing functionally significant joint contractures. Thereafter, relative to patients who stayed in the ICU for just 2 to 3 weeks, the adjusted OR was greater among those who stayed for 5 to 8 weeks and was even higher among those who stayed for 8 weeks or more. Neither sex nor age played a role in the occurrence of any joint contractures in this population. The rate of joint contracture among patients who were admitted to intensive care for a neurologic or vascular disease and among those who received neuromuscular blockade was similar to that of other patients. Conversely, receiving steroids protected against any joint contractures.

One of the most important findings was the potential persistence of joint contractures until the time of discharge home. Our data indicate that joint contractures did not resolve spontaneously before discharge. About one-quarter of the patients were discharged to home with, on average, 2 joint contractures severe enough to interfere with daily activities. ${ }^{8,17,19,21-26}$

Several previous reports have mentioned persistent functional deficits after immobility. ${ }^{2,5,8,15,16,28,29}$ Joint contractures have been identified as a potentially important cause of such deficits, but their prevalence and risk factors have not been quantified. ${ }^{13,16}$ The severity in the restriction of range of motion and the location of a joint contracture determine the patient's functional limitations. Upper limb contractures impair tasks such as showering, dressing, feeding, hand to occiput and hand to perineum; ; ${ }^{15,26}$ lower limb contractures affect ambulation $^{5,8,10,28,30}$ and increase the risk of falls. ${ }^{30}$ Of the $39 \%$ of patients in our study who had any contractures, most (85\%) had I or more contractures with severity that was considered functionally important. For patients with physical occupations and for athletes in virtually all sports, a loss of even a few degrees of the full range of motion may be detrimental to performance. ${ }^{22-25}$

Contracture at a single joint may induce compensatory strategies. Contractures of multiple joints compound the patient's difficulties in performing activities of daily living and leisure pastimes and impose a burden on health care providers and on family members. ${ }^{5,8}$ Contractures of normal joints subjected to immobility are theoretically preventable. In this tertiary care ICU, I.25 full-time physiotherapists and a 0.75 full-time occupational therapist (with assistance from nurses for positioning) were responsible for 24 intensive care beds. However, our data suggest that these usual monitoring and preventive activities were insufficient to prevent the joint contractures.

These data concur with findings of alterations of fibrosis, ${ }^{7}$ synovial shortening ${ }^{31}$ and decreased synoviocyte proliferation $^{32}$ in the joint capsule of rats, measured as early as 2 weeks after immobilization of a normal joint and continuing for the next 30 weeks. The dose-response relation between exposure to intensive care and development of joint contracture supports immobility as a key pathophysiologic risk factor for joint contractures, without a supplemental contribution from affected neurologic systems. Given that multiple 
contractures were present, immobility related to multiple local causes (e.g. arterial or venous catheters, restraints, pressure sores) or generalized immobility can be incriminated. Our results are consistent with experimental literature showing that exogenous or endogenous steroid hormones improve the elasticity of periarticular soft tissues. ${ }^{33-35}$

Our study had limitations. Our range-of-motion data relied on the chart entries of health care professionals with different measuring and charting patterns. We analyzed

Table 2: Demographic characteristics of patients who stayed in the intensive care unit for 2 weeks or longer (admitted between January 2003 and March 2005)

\begin{tabular}{|c|c|}
\hline Variable & $\begin{array}{c}\text { No. (\%) of patients* } \\
n=155\end{array}$ \\
\hline Age at admission, yr, mean (SD) & $59.6(15.5)$ \\
\hline \multicolumn{2}{|l|}{ Sex } \\
\hline Male & $94(60.6)$ \\
\hline Female & $61(39.4)$ \\
\hline \multicolumn{2}{|l|}{ Admission diagnosis } \\
\hline Acute or chronic respiratory disease $†$ & $80(51.6)$ \\
\hline Cancer & $36(23.2)$ \\
\hline Neurologic or vascular disease $\neq$ & $26(16.8)$ \\
\hline Sepsis & $27(17.4)$ \\
\hline APACHE II severity score, mean (SD) & $20.6(7.4)$ \\
\hline \multicolumn{2}{|l|}{ Comorbidity } \\
\hline $\begin{array}{l}\text { Severe cardiac disease (New York } \\
\text { Heart Association class III or IV) }\end{array}$ & $2(1.3)$ \\
\hline Chronic lung disease & $16(10.3)$ \\
\hline Chronic renal failure & $6 \quad(3.9)$ \\
\hline $\begin{array}{l}\text { Neuromuscular condition, } \\
\text { cerebrovascular accident, paraplegia, } \\
\text { quadriplegia }\end{array}$ & $26(16.8)$ \\
\hline AIDS & $2(1.3)$ \\
\hline Diabetes mellitus (type 1 or 2 ) & $116(74.8)$ \\
\hline Cancer & $27(17.4)$ \\
\hline $\begin{array}{l}\text { Length of stay in intensive care unit, } \\
\text { wk, median (interquartile range) }\end{array}$ & $3.1(2.4-5.0)$ \\
\hline $\begin{array}{l}\text { Duration of invasive mechanical } \\
\text { ventilation, } d \text {, median (interquartile } \\
\text { range) }\end{array}$ & $13(5-19)$ \\
\hline \multicolumn{2}{|l|}{ Co-interventions } \\
\hline Neuromuscular blockade & $40(34.8)$ \\
\hline Steroids§ & $95(91.3)$ \\
\hline $\begin{array}{l}\text { Length of stay in hospital, wk, median } \\
\text { (interquartile range) }\end{array}$ & $6.6(4-11)$ \\
\hline
\end{tabular}

Note: $\mathrm{SD}=$ standard deviation, $\mathrm{APACHE}=$ Acute Physiology and Chronic Health Evaluation.

*Unless stated otherwise.

†Acute respiratory distress syndrome, acute respiratory failure, exacerbation of chronic obstructive pulmonary disease, pneumonia, pulmonary edema, pleural effusion, thoracotomy or pneumonectomy.

‡Cerebrovascular accident, acute or chronic inflammatory demyelinating polyneuropathy, altered level of consciousness, paraplegia or quadriplegia, aortic abdominal aneurysm, cardiac arrest, congestive heart failure or myocardial infarction.

§Hydrocortisone, prednisone, prednisolone, methylprednisolone or dexamethasone. only quantitative entries; cases with non-numeric, qualitative reporting of contractures and cases with no report of contracture (where contracture might have been present but went unrecorded) were defined as no contracture. This limitation would lead to underestimation of the true incidence of joint contractures. Baseline range of motion was unavailable, so some patients might have had one or more joint contractures before admission to the ICU, which would lead to overestimation of the incidence of contractures. Furthermore, not all directions or all joints were assessed for all patients. Data were not extracted for extension, external rotation, internal rotation or adduction of the shoulder; pronation-supination of the elbow; abduction, adduction, internal rotation or external rotation of the hip; or flexion or inversion-eversion of the ankle. Small joints such as the wrist, temporomandibular joint, and the joints of the hands, fingers, feet, toes and neck were not included in our study. The limited number of range-of-motion directions and the limited number of joints studied would lead to underestimation of the incidence of joint contractures. Finally, the retrospective design did not allow us to question patients to confirm the limitations associated with joint contracture we defined as functionally significant. Rather, we based our definition on authoritative literature involving measurement of functional limitations based on the range of motion of individual joints.

Our findings imply that patients requiring a lengthy stay in the ICU should be monitored and treated to prevent the appearance of joint contractures that could persist long after the patient is sent home. The lack of complete reversibility at discharge to home that we observed suggests that the natural evolution of joint contractures is not benign and that an ex-

Table 3: Numbers of patients and joints affected by contractures at the time of transfer out of the intensive care unit (ICU) and immediately before or at the time of discharge to home

\begin{tabular}{|lcc}
\hline Variable & \multicolumn{1}{c}{$\begin{array}{c}\text { Any } \\
\text { contracture }\end{array}$} & $\begin{array}{c}\text { Functionally } \\
\text { significant } \\
\text { contracture }\end{array}$ \\
\hline $\begin{array}{l}\text { No. (\%) of patients with } \\
\geq 1 \text { contracture }\end{array}$ & & \\
\hline On transfer out of ICU & $61 / 155(39)$ & $52 / 155(34)$ \\
\hline On discharge to home* & $50 / 147(34)$ & $34 / 147(23)$ \\
\hline No. of joints affected & & 144 \\
\hline On transfer out of ICU & 212 & 90 \\
\hline On discharge to home & 182 & $13(9)$ \\
\hline $\begin{array}{l}\text { Type of joint affected on } \\
\text { transfer out of ICU, no. (\%) }\end{array}$ & & $49(34)$ \\
\hline Shoulder & $24(11)$ & $18(12)$ \\
\hline Elbow & $76(36)$ & $17(12)$ \\
\hline Hip & $30(14)$ & $47(33)$ \\
\hline Knee & $31(15)$ & \\
\hline Ankle & $51(24)$ & \\
\hline
\end{tabular}

*On transfer out of ICU, 8 patients were discharged to a regional hospital and were lost to follow-up. 
pectation of spontaneous recovery could lead to increases in disability in this patient population. These data also underscore the difficulty of treating established joint contractures. Usual hospital care and rehabilitation in a large Canadian academic urban centre were insufficient to reverse the contracture process.

Our study suggests that prevention of joint contractures should be considered a central issue for critical care patients, akin to prevention of thromboembolic events and stress ulcers.
As a rule, patients are admitted to the ICU because of major organ failure, not as a result of joint problems. However, prolonged immobility of normal joints predisposes critically ill patients to the development of contractures. In our study, many patients who were saved from life-threatening illnesses left the hospital with contractures severe enough to cause functional impairment. Joint contractures acquired in the ICU may lead to substantial costs associated with increased length of stay in hospital; increased need for rehabilitation treatments, outpa-

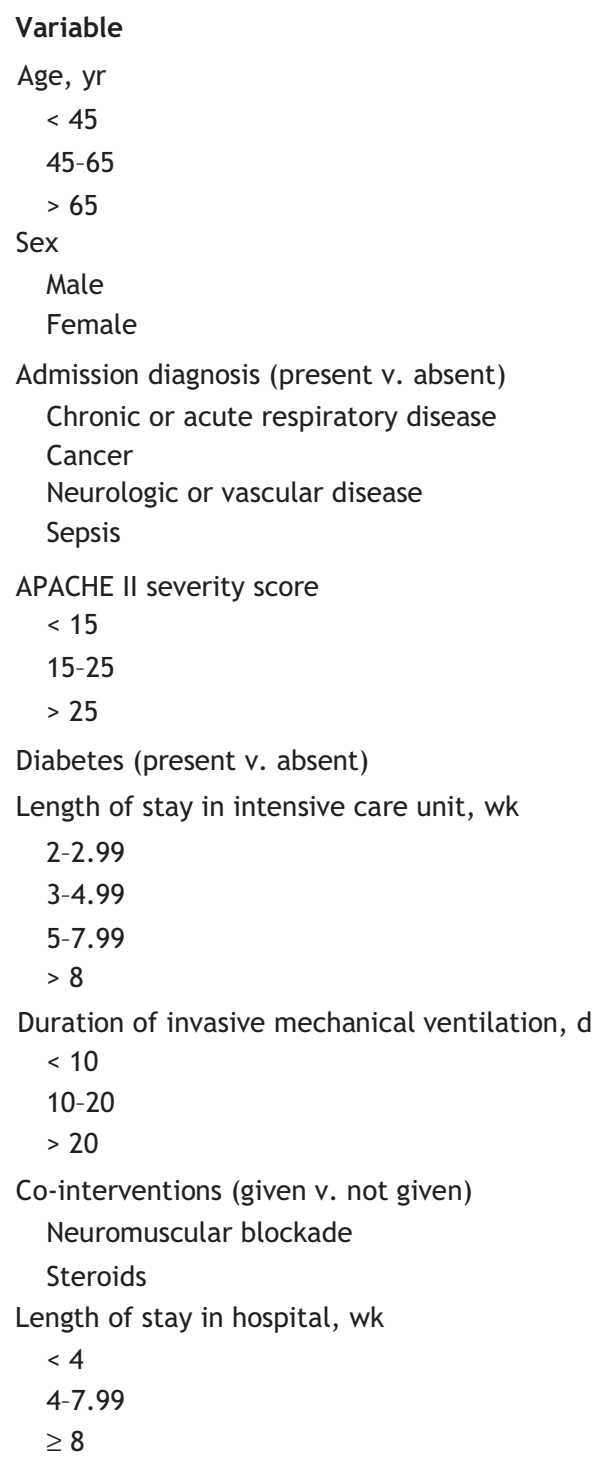

Adjusted OR (95\% Cl)

1.00 [ref]

$0.46(0.15-1.44)$

$0.82(0.26-2.54)$

1.00 [ref]

$0.75(0.34-1.65)$

$1.59(0.68-3.69)$

$0.43(0.16-1.14)$

$1.54(0.55-4.31)$

$0.80(0.26-2.42)$

1.00 [ref]

$1.23(0.45-3.37)$

$0.72(0.23-2.30)$

$0.73(0.30-1.76)$

1.00 [ref]

$1.02(0.37-2.83)$

$1.81(0.48-6.70)$

7.09 (1.29-38.9)

1.00 [ref]

$1.67(0.66-4.21)$

$2.88(0.85-9.84)$

$2.07(0.82-5.24)$

$0.35(0.14-0.83)$

1.00 [ref]

$1.23(0.39-3.89)$

$1.23(0.34-4.46)$

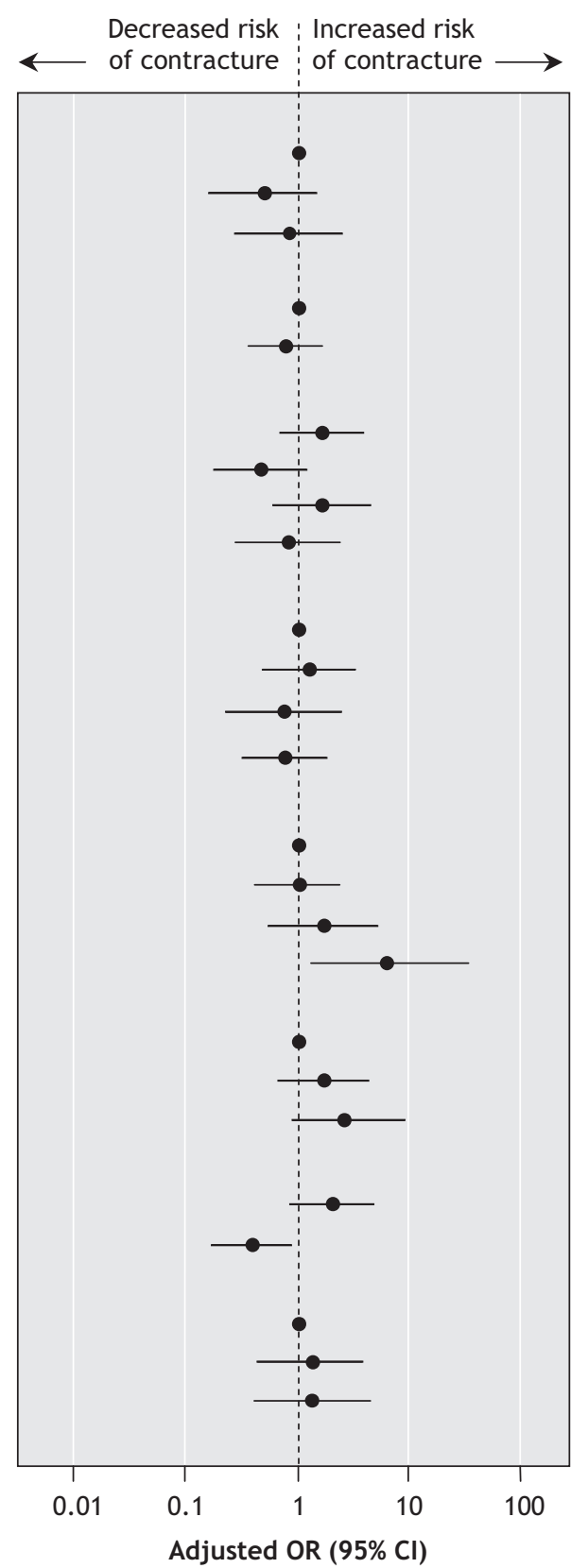

Figure 2: Adjusted odds of experiencing any joint contracture. The results are based on a single multivariable model simultaneously including the demographic variables age and sex, presence of diabetes mellitus as a comorbidity, admission diagnosis, Acute Physiology and Chronic Health Evaluation (APACHE II) severity score, length of stay in the intensive care unit, duration of invasive mechanical ventilation, co-interventions (specifically neuromuscular blockade and steroids) and length of stay in the hospital. For definitions of variables see Table 2. Note: ref = reference group. 


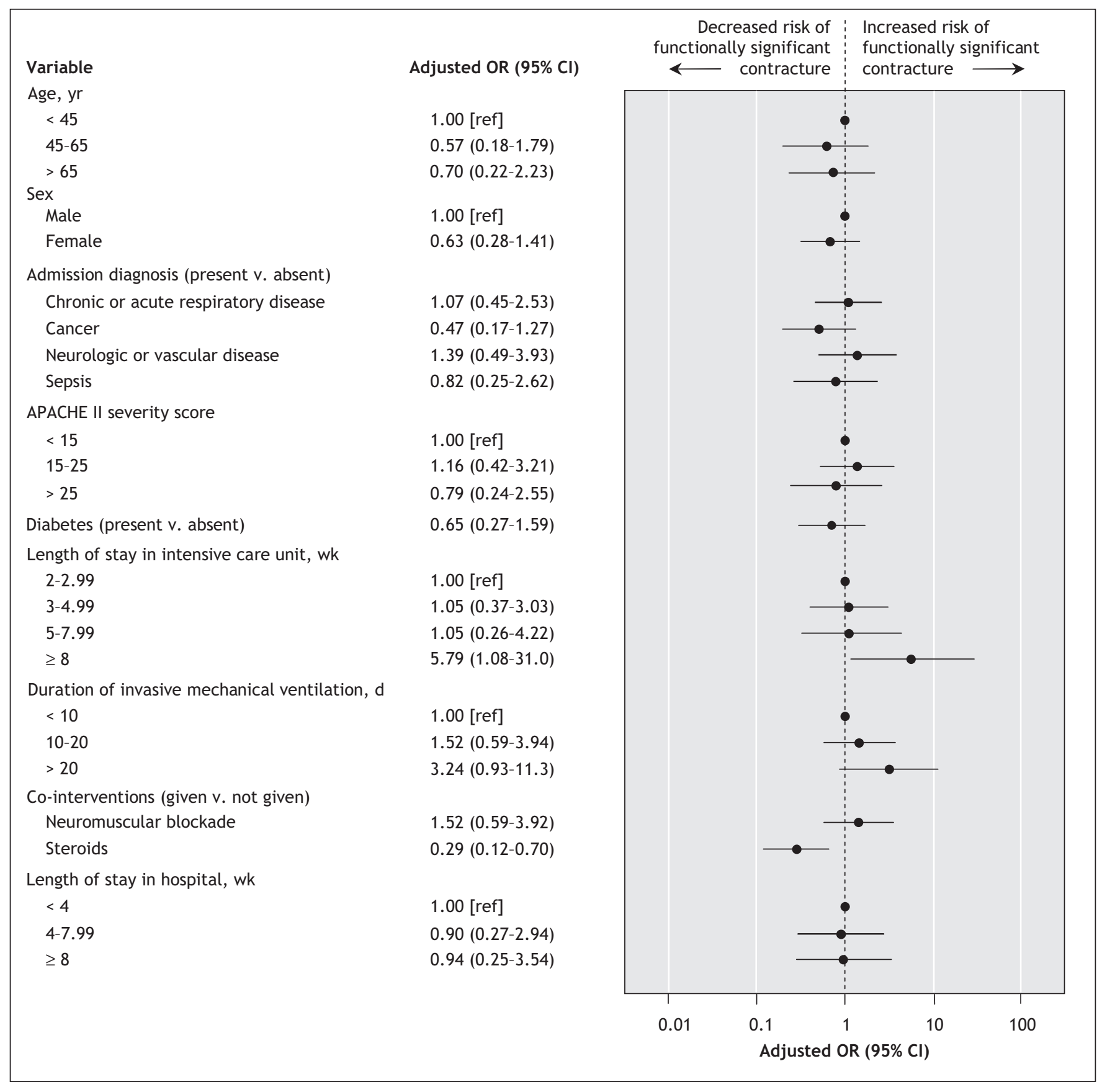

Figure 3: Adjusted odds of experiencing a functionally significant joint contracture. The results are based on a single multivariable model simultaneously including the demographic variables age and sex, presence of diabetes mellitus as a comorbidity, admission diagnosis, Acute Physiology and Chronic Health Evaluation (APACHE II) severity score, length of stay in the intensive care unit, duration of invasive mechanical ventilation, co-interventions (specifically neuromuscular blockade and steroids) and length of stay in hospital. For definitions of variables see Table 2 . Note: ref = reference group.

tient treatments and use of devices for activities of daily living or gait; increased need for personal care at home; and loss of productivity due to inability to return to work.

\section{Conclusions}

Thirty-nine percent of patients staying for 2 weeks or more in an academic hospital ICU experienced joint contractures, often in more than I joint. Most of these contractures were of an extent documented to impair function and persisted until the time of discharge to home. This study indicates a need for prospective multicentre observational studies to further study joint contracture in the intensive care setting. The magnitude of the clinical problem also invites concerted actions to better understand the cause of contractures and develop effective interventions. 
This article has been peer reviewed.

Competing interests: None declared.

Disclaimer: Paul Hébert is a coauthor of this article. As Editor-in-Chief of $C M A J$, he was not involved in the selection of peer reviewers or the vetting of the manuscript before its acceptance.

Contributors: Heidi Clavet, Paul Hébert, Dean Fergusson and Guy Trudel contributed to the conception and design of the project. Heidi Clavet drafted the article and was responsible for acquisition of the data. Steve Doucette contributed to the analysis and interpretation of the data and drafted the text describing the data analysis. Guy Trudel contributed substantively to the analysis and interpretation of the data. Paul Hébert, Dean Fergusson and Guy Trudel revised the article for important intellectual content. All of the authors gave final approval of the version to be published.

Acknowledgement: The preliminary results of this study were presented at the annual congress of the Canadian Association of Physical Medicine and Rehabilitation, June I3-I6, 2007, London, Ontario.

\section{REFERENCES}

I. Farmer SE, James M. Contractures in orthopaedic and neurological conditions: a review of causes and treatment. Disabil Rehabil 200I;23:549-58.

2. Yarkony GM. Prevention and management of contractures. In: Kapan PE, editor. The practice of physical medicine. Springfield (IL): Thomas Books; I984. p. 526-37.

3. Akeson WH, Amiel D, Woo SLY. Immobility effects on synovial joints. The pathomechanics of joint contracture. Biorheology I980;17:95-IIO.

4. Leong $B$. The vegetative and minimally conscious states in children: spasticity, muscle contracture and issues for physiotherapy treatment. Brain Inj 2002;16:217-30.

5. Fox P, Richardson J, McInnes B, et al. Effectiveness of a bed positioning program for treating older adults with knee contractures who are institutionalized. Phys Ther 2000;80:363-72.

6. Trudel G, Uhthoff HK. Contractures secondary to immobility: Is the restriction articular or muscular? An experimental longitudinal study in rat knees. Arch Phys Med Rehabil 2000;81:6-I3.

7. Matsumoto F, Trudel G, Uhthoff HK. High collagen type I and low collagen type III levels in knee joint contracture: an immunohistochemical study with histological correlate. Acta Orthop Scand 2002;73:335-43.

8. Mollinger LA, Steffen TM. Knee flexion contractures in institutionalized elderly: prevalence, severity, stability and related variables. Phys Ther 1993;73:437-46.

9. Dittmer DK, Teasell R. Complications of immobilization and bed rest. Part I: Musculoskeletal and cardiovascular complications. Can Fam Physician I993;39:1428-32, I435-37.

Io. Souren LEM, Franssen EH, Reisberg B. Contractures and loss of function in patients with Alzheimer's disease. J Am Geriatr Soc i995;43:650-5.

II. Laneuville O, Zhou J, Uhthoff HK, et al. Genetic influences on joint contractures secondary to immobilization. Clin Orthop Relat Res 2007;456:36-4I.

I2. Winkelman C. Inactivity and inflammation in the critically ill patient. Crit Care Clin 2007;23:2I-34.
I3. Herridge MS, Cheung AM, Tansey CM, et al. One-year outcomes in survivors of the acute respiratory distress syndrome. N Engl J Med 2003;348:683-93.

I4. Moriyama H, Yoshimura O, Sunahori H, et al. Comparison of muscular and articular factors in the progression of contractures after spinal cord injury in rats. Spinal Cord 2006;44:I74-8I.

I5. Turton AJ, Britton E. A pilot randomized controlled trial of a daily muscle stretch regime to prevent contractures in the arm after stroke. Clin Rehabil 2005;19:600-I2.

I6. Fergusson D, Hutton B, Drodge A. The epidemiology of major joint contractures: a systematic review of the literature. Clin Orthop Relat Res 2007;456:22-9.

I7. Dutton M. Orthopaedic examination, evaluation and intervention. New York: McGraw-Hill; 2004.

I8. Morrey BF. The elbow and its disorders. 3rd ed. Philadelphia: WB Saunders; 2000.

I9. Fagerson TL. The hip handbook. Boston: Butterworth-Heinemann; I998.

20. Cailliet R. Knee pain and disability. 3rd ed. Philadelphia: F.A. Davis Co; 1992.

2I. Singer BJ, Dunne JW, Singer KP, et al. Non-surgical management of ankle contracture following acquired brain injury. Disabil Rehabil 2004;26:335-45.

22. Vad VB, Gebeh A, Dines D, et al. Hip and shoulder internal rotation range of motion deficits in professional tennis players. J Sci Med Sport 2003;6:7I-5.

23. Ellenbecker TS, Ellenbecker GA, Roetert EP, et al. Descriptive profile of hip rotation range of motion in elite tennis players and professional baseball. Am J Sports Med 2007;35:I37I-6.

24. Ellenbecker TS, Roetert EP, Bailie DS, et al. Glenohumeral joint total rotation range of motion in elite tennis players and baseball pitchers. Med Sci Sports Exerc 2002;34:2052-6.

25. Khan K, Roberts P, Nattrass C, et al. Hip and ankle range of motion in elite classical ballet dancers and controls. Clin J Sport Med I997;7:174-9.

26. Tang C, Roidis N, Itamura J, et al. The effect of simulated elbow arthrodesis on the ability to perform activities of daily living. J Hand Surg [Am] 200I;26:II46-50.

27. Knaus WA, Draper EA, Wagner DP, et al. APACHE II: a severity of disease classification system. Crit Care Med I985;13:818-29.

28. Steffen TM, Mollinger LA. Low-load, prolonged stretch in the treatment of knee flexion contractures in nursing home residents. Phys Ther 1995;75:886-97.

29. Leblebici B, Adam M, Bagis S, et al. Quality of life after burn injury: the impact of joint contracture. J Burn Care Res 2006;27:864-8.

30. Lim MR, Huang RC, Wu A, et al. Evaluation of the elderly patient with an abnormal gait. JAm Acad Orthop Surg 2007;15:107-17.

3I. Trudel G, Seki M, Uhthoff HK. Synovial adhesions are more important than pannus proliferation in the pathogenesis of knee joint contracture following immobilization: an experimental investigation in the rat. J Rheumatol 2000;27:35I-7.

32. Trudel G, Jabi M, Uhthoff H. Localized and adaptive synoviocyte proliferation characteristics in rat knee joint contractures secondary to immobility. Arch Phys Med Rehabil 2003;84:1350-6.

33. Akeson WH, Woo SLY, Amiel D, et al. Value of $\mathrm{I}_{7} \beta$-oestradiol in prevention of contracture formation. Ann Rheum Dis i976;35:429-36.

34. Michelsson JE, Juntunen S, Valtakari T. Methylprednisolone has a preventive effect on the development of radiological changes, thickening and stiffening of the rabbit knee following immobilization. Clin Exp Rheumatol 1990;8:439-43.

35. Ohtera K. Zobitz ME, Luo ZP, et al. Effect of pregnancy on joint contracture in the rat knee. J Appl Physiol 2002;92:1494-8.

Correspondence to: Dr. Guy Trudel, The Rehabilitation Centre, 505 Smyth Rd., Ottawa ON KIH 8M2; fax 613 737-7056; gtrudel@ottawahospital.on.ca 